\title{
Las imprentas nómadas. Artefactos, conspiraciones y propaganda
}

Jorge Omar Mora

(iD) https://orcid.org/oooo-0003-3876-4295

Universidad de Guadalajara, México

omarmora811@gmail.com

Alessandro Corubolo y Maria Gioia Tavoni, Las Imprentas nómadas. Artefactos, conspiraciones y propaganda, Buenos Aires, Ampersand, 2019, 316 pp. ISBN 978987-416130-7

A finales de la década de 1970 aparecieron los dos volúmenes de La imprenta como agente de cambio. Comunicación y transformaciones culturales en la Europa moderna temprana, de Elizabeth Einsenstein. En este estudio la autora sugiere que, con la introducción de la imprenta en Europa los patrones de comunicación padecieron una transformación irrevocable, a la vez que condicionaron los grandes movimientos sociales y políticos de la época. Y aunque esta obra ha sido una de las más influyentes sobre cultura impresa en la modernidad temprana, en las últimas dos décadas se ha señalado su carácter determinista y simplificador (Johns, 1998; Darnton, 2010). Al margen de los límites de su propuesta, la ruta trazada por Einsenstein (2010) ha sido recorrida insuficientemente para explicar "los efectos y consecuencias de la invención de Gutenberg” (p. 3). No obstante, los esfuerzos por

\section{c) (i) (8)}

4.0 Internacional

Secuencia. Reseñas, 2021

http://secuencia.mora.edu.mx
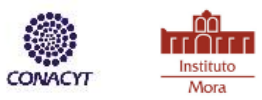
contribuir a esta empresa han sido múltiples y desde variadas disciplinas, constituyendo un campo de estudio sólido, aún en expansión.

Dentro de las vetas que han contribuido a la expansión y renovación de este campo de estudio se encuentra una de muy reciente aparición, que gira en torno a la "movilidad de los oficios del libro" y se centra en la impresión in itinere. Expresión de este novedoso interés es la obra de Maria Gioia Tavoni y Alessandro Corubolo titulada Torchi e stampa al seguito, publicada en 2016 y traducida al español en 2019 por Nora Sforza como Las imprentas nómadas. Artefactos, conspiraciones y propaganda, bajo el sello de Ampersand en la colección Scripta Manent.

Este trabajo ubica su génesis como ponencia en el Congreso Internacional "Mobilitá dei mestreri del libro tra quattrocento e seicento", celebrado en la ciudad de Roma en 2012. En aquel momento, Tavoni, catedrática en historia del libro y experta en bibliografía, propuso un acercamiento al fenómeno de la impresión itinerante o in itinere, que por entonces se pensaba como una práctica poco recurrente, esporádica. Sin embargo, a partir de un primer esbozo, el proyecto reveló una diversidad de casos y una riqueza de fuentes que constituyeron una amplia cartografía de la impresión en movimiento. Desde aquel primer momento, el proyecto al que se sumó Alessandro Corubolo, reconocido por su conocimiento amplio en bibliofilia, se convirtió en una empresa un poco más ambiciosa.

En principio, los autores se proponen indagar en las condiciones que posibilitaron la impresión itinerante, así como en las motivaciones de quienes participaron de esta práctica en función de sus contextos sociohistóricos concretos. De esta manera, aunque las máquinas son las protagonistas de la obra, los autores se centran en el rol que estas desempeñaron en guerras, batallones, ferias, festivales, 
visitas episcopales, viajes, la Resistencia antifascista, y un etcétera de episodios. Para tal fin, se echa mano de un corpus documental sólido y amplio para proceder per exempla. Destaca en este sentido el apoyo iconográfico: se busca ilustrar los ejemplos con materiales gráficos, y aunque no siempre se logra, es uno de los aportes más significativos del trabajo.

Para hablar de la impresión en movimiento, Tavoni y Corubolo parten de una caracterización de las prensas, que básicamente se sintetiza en los criterios que siguieron para la selección de los casos de estudio: miniaturización, agilidad, inmediatez y estabilidad. Estos elementos ampliamente descritos e ilustrados permiten a los autores trazar el desarrollo histórico de los dispositivos en diferentes sitios. Y precisamente ahí radica un aporte más de la obra. Pese a que el grueso del estudio se centra en Italia, acaso el centro de Europa, muestra múltiples ejemplos verificados en otras latitudes, que van del Tíbet a Estados Unidos, pasando por Australia, la Antártida y un par de cuerpos acuáticos, como el océano Atlántico. La amplitud de los contextos geográficos revisados da cuenta de la complejidad y la heterogeneidad de un fenómeno a gran escala, y para el que este trabajo apenas funge como botón de muestra.

Valga señalar que la itinerancia de la impresión no es atribuible únicamente a las prensas. Los medios de transporte juegan un papel importante aquí. Este papel es recuperado en la obra como parte central de la preocupación por la movilidad de la impresión. Ya sean prensas tipográfica y calcográfica montadas sobre carros para las fiestas solemnes de la Inmaculada Concepción en Valencia durante el siglo XVII; prensas móviles para el registro itinerante de personas bautizadas durante las visitas pastorales del obispo Constantino Zani, en la diócesis de Imola; imprentas E-ISSN 2395-8464 https://doi.org/10.18234/secuencia.v0i0.1966 
ambulantes transportadas en góndolas de regate durante las visitas de los Habsburgo a Venecia en el siglo XIX; o un taller tipográfico instalado por iniciativa de León Trotski en el vagón de un tren que, en 1918, recorría el territorio ruso mientras diagramaba e imprimía el periódico V PUTI, la relación entre movilidad e impresión se mantuvo en función de diversas y variadas motivaciones y finalidades. Y es en este punto donde radica el núcleo del estudio.

“¿A qué responden las imprentas móviles o itinerantes?” Se preguntan Tavoni y Corubolo, para indagar en los motivos que animaron a hombres y mujeres a participar en una práctica que resultó mucho más extendida y diversa histórica y geográficamente, de lo que pensaron al inicio de sus pesquisas. La justificación económica queda rebasada y es reemplazada por la casuística. Sólo pueden explicarse los usos de estos dispositivos y sus tipologías en relación con las necesidades de eventos históricos particulares. Así, por ejemplo, en medio de la aristocracia francesa del siglo XVIII, se tienen noticias de la difusión de las presse de cabinet como pasatiempos de reyes y príncipes, y por extensión en la burguesía alta y culta. El siglo XIX inglés, con su prosperidad económica, la ausencia de revoluciones, el avance industrial y de las libertades, propició una proliferación de prensas de uso doméstico, bajo el lema every man his own printer. Más allá de estos usos, por ocio o entretenimiento, se constata la función estratégica de las prensas en guerras, trincheras, reclusión, clandestinidad y repatriación. En estos casos, además de informar y difundir estrategias con relativa celeridad en medio de los campos de batalla, la impresión en movimiento ayudó a sostener regímenes, mantener el ánimo de los combatientes, entretener a los soldados, consolar al exiliado y, según se muestra en el último capítulo, a la liberación femenina. 
Ahora bien, para ponderar este trabajo, es preciso proceder en dos vías. La primera consiste en evaluar la coherencia de la obra en función de los objetivos planteados. La segunda amerita estimar sus aportes en términos historiográficos. Hay que apuntar entonces, en primer lugar, que los objetivos del libro se cumplen de forma eficaz. Al echar mano de la historia social de la cultura escrita, el trabajo reconstruye los contextos de producción, emisión y circulación de los impresos, destacando las relaciones que median cada uno de los procesos -en la medida que las fuentes lo permiten- y estableciendo explicaciones plausibles de las condiciones de posibilidad de los usos y tipologías de los dispositivos en cada caso. Si bien la cartografía de casos mostrados por los autores no es exhaustiva, metodológicamente resulta ilustrativa de los alcances que tiene un fenómeno heterogéneo como lo fue la impresión itinerante.

En segundo lugar, según se ha mencionado al inicio, este trabajo se inserta dentro de los marcos y preocupaciones de la historia cultural, la historia intelectual, la historia de la lectura y la historia social de la cultura escrita. En décadas recientes, estas perspectivas han desarrollado un interés compartido en torno a la materialidad del objeto escrito/impreso, así como sus condiciones de producción, circulación, consumo y, en ocasiones, preservación. Atendiendo a este interés, el estudio de Corubolo y Tavoni explora las condiciones que posibilitan la impresión en movimiento, que implica el análisis de dispositivos pequeños, portátiles, livianos, a la par de sus impresos efímeros y excepcionales. En este sentido, Imprentas nómadas relativiza los fines de la invención de Guntenberg, definiendo una línea de investigación inédita, orientada a la observación de las particularidades de la impresión in itinere, basada en un vasto andamiaje interdisciplinario. 
Para la historiografía latinoamericana, esta obra resulta pertinente y, sobre todo, original; pero su relevancia puede cuestionarse. $\mathrm{Y}$ es que más allá de no establecer un diálogo con la literatura de la región, cuyo campo se ha desarrollado notablemente en las últimas dos décadas, no hay un solo caso que le refiera. Y aunque esto puede obedecer a distintos motivos, sobre todo, rebasar los objetivos de investigación planteados por los autores, quienes reconocen que no se trata de un muestreo exhaustivo de casos, también puede ser síntoma de la ausencia de una práctica privativa/exclusiva del 'norte global'. Esto debe animar futuras investigaciones desde América Latina para explorar otras finalidades que pudiera haber desarrollado la imprenta y relativizar su estabilidad. Ponderar un mayor número de usos y tipologías de la imprenta, ayudará a comprender mejor el fenómeno de la cultura impresa en las sociedades hispanoamericanas. En tal caso, las Imprentas nómadas de Tavoni y Corubolo ofrecen un modelo metodológico adecuado y viable.

Para concluir, valga destacar un par de elementos más sobre el libro. Por un lado, los lectores contemplados. Pese a que es un trabajo riguroso, de corte académico, su construcción y presentación lo vuelven bastante accesible a un público más amplio que el constituido por especialistas en la materia. Si se considera, además, la abundante y rica iconografía que acompaña a los relatos se está frente a un libro por demás atractivo. Por otro lado, se trata de un trabajo interdisciplinario que incluye al género como una variable importante que atraviesa todo el texto, para destacar el papel de mujeres escritoras, editoras, tipógrafas e impresoras, en distintos contextos y con motivaciones variadas. Finalmente, según se estila en publicaciones recientes sobre la materia, la obra repara en una serie de reflexiones 
proféticas sobre el devenir de la imprenta; reflexiones que se debaten entre la posibilidad tecnológica y la utopía.

Referencias

Darnton, R. (2010). El beso de Lamourette. Buenos Aires: Fondo de Cultura Económica.

Einseinstein, E. (2010). La imprenta como agente de cambio. Comunicación y transformaciones culturales en la Europa moderna temprana. México: Fondo de Cultura Económica.

Johns, A. (1998). The Nature of the Book: Print and Knowledge in the Making. Chicago: Chicago University Press. 